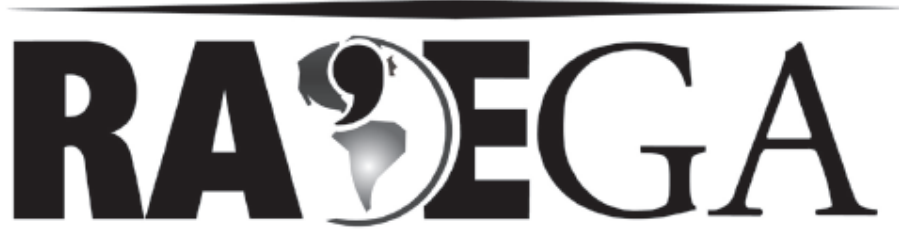

O ESPAÇO GEOGRÁFICO EM ANÁLISE

\title{
PERCEPÇÃO AMBIENTAL NO TURISMO DO PARQUE ECOLÓGICO CACHOEIRA DO URUBU NOS MUNICÍPIOS DE ESPERANTINA E BATALHA NO ESTADO DO PIAUÍ
}

\section{ENVIRONMENTAL PERCEPTION IN TOURISM OF ECOLOGICAL PARK WATERFALL OF URUBU IN MUNICIPALITIES ESPERANTINA AND BATALHA IN THE STATE OF PIAUÍ}

\author{
Accyolli Rodrigues Pinto de Sousa ${ }^{1}$ \\ José Luis Lopes Araújo ${ }^{2}$ \\ Wilza Gomes Reis Lopes ${ }^{3}$
}

\section{RESUMO}

No turismo há características sociais e econômicas que são particulares de um atrativo turístico; aliada a esses elementos, a percepção ambiental é um processo relevante, em razão de mostrar características subjetivas relacionadas à prática turística, caracterizada pela relação: turista e meio ambiente. Dessa forma, a compreensão do turismo realizado no Parque Ecológico Cachoeira do Urubu, no Estado do Piauí, é importante pela frequência de visitantes no período chuvoso. Assim, a relevância da percepção ambiental no Parque possibilitou o entendimento às concepções dos turistas no que se refere à conservação do local, limpeza, infraestrutura, e experiência afetiva com o espaço.

Palavras-chave: Turista; Unidade de Conservação; Lugar; Subjetividade.

\footnotetext{
1 Licenciado em Geografia pela UFPI. Mestre em Desenvolvimento e Meio AmbienteUFPI/TROPEN/PRODEMA.Professor do Instituto Federal de Educação, Ciência e Tecnologia do PiauíIFPI. accyolli.p@hotmail.com

${ }^{2}$ Geógrafo. Doutor em Geografia Humana, pela USP. Professor do Mestradoem Desenvolvimento e Meio Ambiente/UFPI/TROPEN/PRODEMA. Professor doDepartamento de Geografia e História/CCHL/UFPI. jlla@ufpi.edu.br

${ }^{3}$ Arquiteta. Doutora em Engenharia Agrícola pela Universidade Estadualde Campinas. Professora do Mestrado em Desenvolvimento e MeioAmbiente/UFPI/TROPEN/PRODEMA. Proefessora do Departamento de Construção Civil e Arquitetura/DCCA/CT/UFPI. wilzalopes@hotmail.com
} 


\begin{abstract}
Abstract: In tourism has social and economic characteristics that are particular to a tourist attraction, allied to these factors, the environmental perception is a process of showing relevant because subjective characteristics related to tourist practice characterized by the relationship: tourist and environment. Thus, the understanding of tourism conducted in the Ecological Park Waterfall Urubu in Piauí state is important, because the frequency of visitors during the rainy period. So, the relevance of environmental perception in the Park enabled understand the concepts of tourists with regard to the conservation of the site, cleaning, infrastructure and affectionate experience with the space.
\end{abstract}

Keywords: Tourist; Conservation Unit; Place; Subjectivity.

\title{
Introdução
}

$\mathrm{Na}$ atividade turística ocorrem vários processos de natureza social, econômica, cultural e ambiental. Com relação a isto, nos dias atuais, existe uma discussão que está interligada aos parâmetros citados anteriormente. Este debate relaciona-se com a percepção de que, em alguns casos, representa as atitudes e a apreensão dos elementos naturais e culturais da paisagem pelo observador.

A percepção ambiental é um processo de troca entre o homem e o meio, e vice-versa, sendo definida, por Del Rio (1999, p. 3), como "um processo mental de interação do indivíduo como meio ambiente que se dá através de mecanismos perceptivos propriamente ditos, e, principalmente, cognitivos", fazendo com que a atividade turística tenha maior e melhor significado, por fortalecer os sentimentos que podem ser assimilados na paisagem através dos sentidos.

Este processo é importante pelo fato de mostrar ou ressaltar aspectos subjetivos existentes em um lugar; ou seja, representado por elementos culturais como estilo arquitetônico, dança, culinária e artesanato, e o entendimento do observador para com esses elementos. Juntamente com os aspectos antrópicos, a percepção é utilizada para o entendimento dos aspectos naturais como: praias, cachoeiras, lagos etc. Na visão de Machado e Maciel (2007. p. 296), “A percepção ambiental é, portanto, uma área de estudo capaz de relacionar significados e valores individuais a respeito do ambiente natural".

Esses tipos de espaços são dotados de características especiais, pelo fato de as pessoas estabelecerem relações próximas com o local, tornando-o 
um espaço diferenciado. Tal individualidade surge com base em um processo inerente à percepção - a topofilia - que, conforme Tuan (1980, p. 5), "é o elo afetivo entre a pessoa e o lugar ou ambiente físico".

Busca-se, por meio da percepção ambiental, realizar uma análise dos elementos existentes no espaço. De acordo com Oliveira e Machado (2004), a percepção é o conhecimento que se adquire através do contato atual, direto e imediato com os objetos e com seus movimentos dentro do campo sensorial.

Logo, esse processo é importante pelo fato de conter elementos que possibilitam a construção de experiências individuais, em decorrência dos sentimentos e das ideias formadas na consciência do indivíduo, perante "[...] a resposta dos sentidos aos estímulos externos [...]" (TUAN, 1980, p.4). Nessa dinâmica, o indivíduo absorve as sensações em determinado espaço, seja natural ou construído pelo homem, assimilando, assim, as propriedades contidas através de seus sentidos, especialmente da visão. Segundo Tuan (1983), o espaço visual com sua nitidez e tamanho difere dos outros espaços percebidos por meio da audição e do tato. A interpretação do local através do olhar é algo relevante para a assimilação das propriedades existentes.

A construção dessa estrutura é feita com auxílio dos sentidos, posto que, nessa discussão sobre percepção e meio ambiente, a visão, olfato, tato e a audição assumem grande funcionalidade na elaboração de um contexto entre a pessoa e o meio no qual ela está relacionada. Dentre os sentidos supraenumerados, a visão possui maior relevância, pelo fato de captar o modo de organização juntamente com os atributos existentes. Para Okamoto (2002, p. 110), os "[...] sentidos são considerados os meios mais importantes para se enxergar a realidade, com predominância aparente da visão". Essas características podem ser relacionadas com a limpeza, a conservação da natureza, depredação dos monumentos naturais, lixo e infraestrutura.

Através dos sentidos, pode-se elaborar um conjunto de elementos que possibilitam criar uma compreensão mais apurada sobre a realidade, tornando possível ao homem construir um panorama das características positivas e também das negativas sobre determinado local, pelo fato de a imagem, o cheiro e o som estimularem às pessoas a construir uma imagem sobre o 
espaço. Assim, dependendo das sensações recebidas, o indivíduo pode criar uma estrutura de atributos relacionados a um local.

Neste processo, pode-se ter uma experiência proveitosa, ao ser capaz de sentir emoções e criar valores positivos ou negativos, em relação a determinado espaço. Para Castello (2007, p. 12), "é possível aceitar-se, então, por trás da identificação de um lugar encontre-se presente todo um processo de valoração do espaço, que muito bem ser atribuído à percepção que as pessoas têm (ou que virão adquirir) a respeito desse espaço".

A discussão sobre percepção está relacionada com a categoria "lugar", pois, nesse tipo de organização espacial, têm-se mudanças no espaço; em consequência, o entendimento sobre a realidade existente difere pelo fato de 0 lugar conter elementos diferenciados como: experiências de vida, manifestação cultural, na identidade local, através dos costumes da população, fazendo com que apareça um recorte espacial diferenciado.

Segundo Tuan (1983, p. 19), "os homens não apenas discriminam padrões geométricos na natureza e criam espaços abstratos na mente, como também procuram materializar seus sentimentos, imagens e pensamentos". 0 lugar é um elemento importante, pois ocorre um modo de organização espacial com particularidades que permitem a elaboração de mudanças, ocorrendo assim o aparecimento de uma nova realidade. De acordo com Moraes (1996), o espaço geográfico propicia leituras na produção dos lugares, através da valorização subjetiva do espaço juntamente com a manifestação da consciência.

Diante das ideias apresentadas, entende-se que os processos de reprodução do espaço podem concorrer para alterações nas relações sociais, em decorrência de elementos externos e internos, por meio da consciência gerada em cada pessoa. Ou seja, dentro de um grupo, pode-se ter uma variedade de ações e concepções que são de grande relevância para a formação da identidade local. A importância de ressaltar essas características é fundamental, como forma de entender os princípios que estão relacionados com essa discussão. 
É importante identificar a percepção ambiental de visitantes que frequentam unidades de conservação, como forma de analisar as relações existentes entre o homem e o meio ambiente. Dessa forma, neste trabalho serão analisadas as percepções, interesses e valores de diferentes atores sociais, em uma unidade de conservação (UC), o Parque Ecológico Cachoeira do Urubu, localizado na microrregião do Baixo Parnaíba Piauiense, inserida na Mesorregião Norte Piauiense.

\section{Metodologia}

A metodologia utilizada na pesquisa fundamentou-se em Tuan (1980), que estabelece a relação entre o sujeito e o ambiente através do fortalecimento dos valores subjetivos para com o meio externo, e ainda em Neiman (2008), que considera a resposta do turista em relação às representações simbólicas do espaço turístico com o propósito de assimilar os aspectos naturais e/ou culturais com o intuito de formar uma identidade entre os frequentadores. Assim, foram discutidos itens referentes aos aspectos físicos do parque, como infraestrutura, limpeza, conservação do ambiente, e manifestações simbólicas relativas ao nível de satisfação obtida e atrativo cultural da visita.

A coleta de informações se respaldou em Cavalcante e Maciel (2008), que propõem uma análise da percepção baseada na observação e no questionamento. Dessa forma foi utilizado o registro fotográfico juntamente com anotações das ações que causaram degradação ambiental no espaço e na aplicação dos formulários com questões para entender os atos e a relação dos visitantes para com o Parque Ecológico Cachoeira do Urubu.

Foram aplicados 80 questionários, no período do Carnaval e da Semana Santa de 2010, pois nessas datas ocorre uma maior frequencia dos visitantes ao parque. $\mathrm{O}$ formulário, predominantemente de caráter qualitativo, foi baseado em metodologia empregada por Pinheiro (2004), em área de estudo e temática semelhante. Era composto de 36 perguntas abertas e fechadas, que abordavam aspectos relativos a simbologia, experiência, nível de conservação, limpeza, expectativa da visita, infraestrutura e atrativos naturais. 
$\mathrm{Na}$ aplicação dos formulários aos visitantes, o tipo de amostragem utilizada foi a probabilística aleatória estratificada (LEITE, 2008), enfocando o grupo de pessoas com idade entre 18 a 60 anos, pois estariam mais aptos a emitir opiniões sobre a atividade turística existente no Parque. Os dados foram tratados através do software Excel 2007.

\section{Caracterização da área da pesquisa}

O Parque Ecológico Cachoeira do Urubu, com área de 7,54 ha, prevê a prática do ecoturismo, no seu decreto de criação. Situa-se no interior da Área de Proteção Integral (APA) da Cachoeira do Urubu, com área de 3.053ha, criada pelo Decreto estadual n. 9.736 de 16 de junho de 1997. A compreensão sobre a percepção ambiental ocorreu através da análise do turismo praticado no Parque Ecológico Cachoeira do Urubu, localizado entre os municípios de Esperantina e Batalha ambos no Estado do Piauí. Mapa 1:

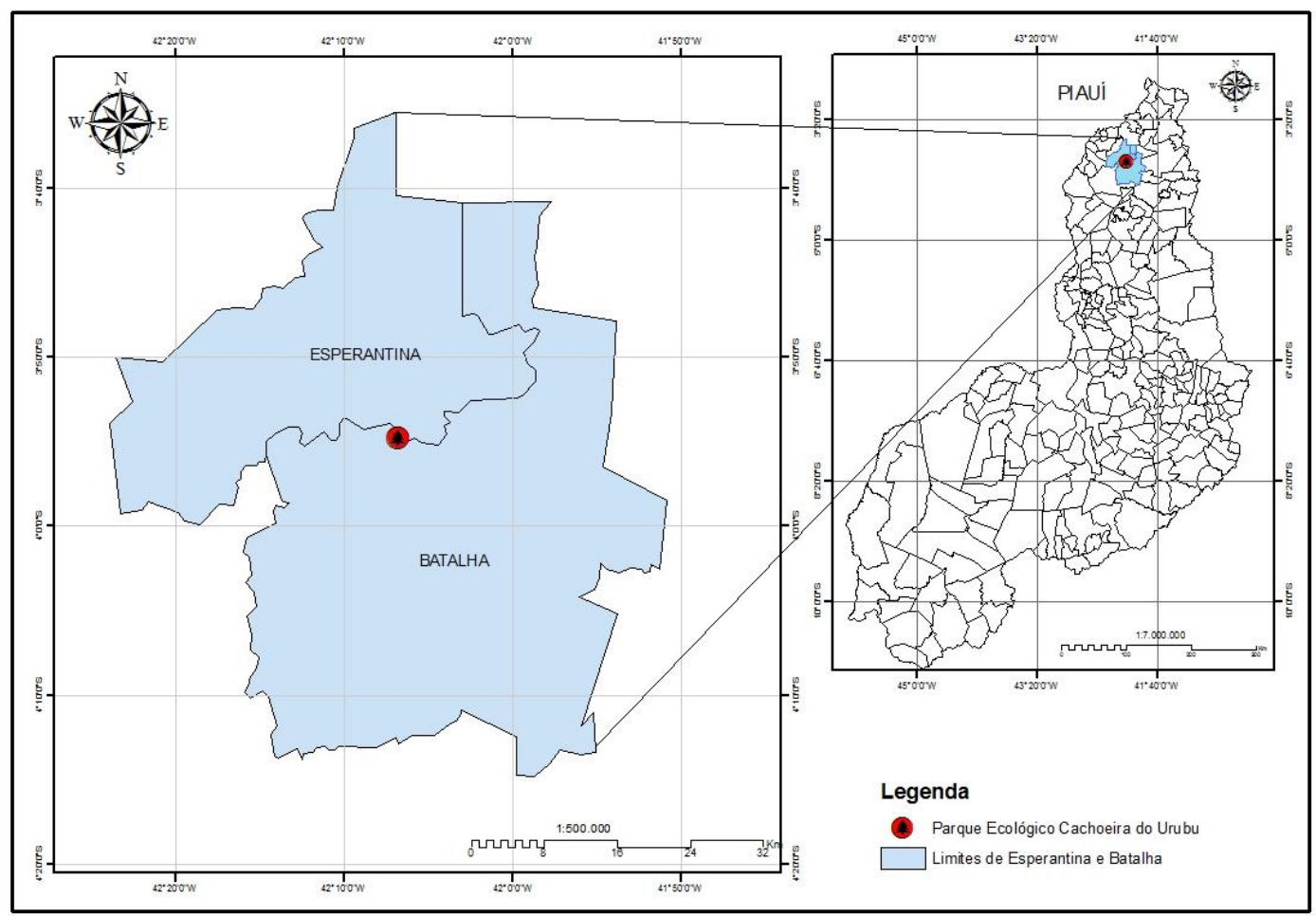

Mapa 1: Parque Ecológico Cachoeira do Urubu. Fonte: Sousa, 2010. 
A Cachoeira do Urubu, na década de 1990, despontava como um importante atrativo turístico. Antes mesmo de sua criação oficial, essa área já era importante para a recreação das pessoas oriundas de várias cidades piauienses e de outros Estados. Outro fator que deve ser considerado para a área de estudo é que o Parque Ecológico Cachoeira do Urubu localiza-se em uma região turística denominada de Polos das Águas, a qual compreende dezessete municípios do Norte do Estado (PIAUÍ, 2009).

O Parque Ecológico Cachoeira do Urubu possui atrações turísticas que estão diretamente ligadas às paisagens naturais, a exemplo de cachoeiras, piscinas naturais, trilhas e feições ruiniformes. Essa UC está diretamente influenciada pelo aumento do volume nas águas do rio Longá, em razão de o período chuvoso da região iniciar em dezembro, prolongando-se até o mês de maio. Isso ocorre pelo fato de os municípios localizados na região Norte do Estado do Piauí terem o regime de precipitação influenciado pela Zona de Convergência Intertropical (ZCIT), que é formada a partir da junção dos ventos alísios de NE e de SE (AYOADE, 2002).

A estrutura geológica do parque é do tipo sedimentar, por estar inserido na bacia sedimentar do Piauí/Maranhão. Detectou-se a presença de rochas sedimentares, como, por exemplo, arenitos avermelhados, brancos e róseos, e ainda conglomerados. No leito rochoso do Rio Longá são encontradas formas de erosão fluvial, tais como: corrasão, causando assim o aparecimento de uma paisagem diferenciada, com a presença de marmitas, as quais podem ser vistas apenas no período seco.

Com relação aos aspectos vegetacionais, o Parque Ecológico Cachoeira do Urubu possui, segundo Silva (2008), ambientes com características de transição, com representatividade florística importante, tendo em vista que, no interior e nas áreas externas dessa UC, é possível encontrar setores da vegetação com características dos Biomas Caatinga e do Cerrado.

É importante ressaltar que nessa UC há moradores no seu interior; que totalizam cinco residências, e, em alguns casos, existem impactos ambientais oriundos da ação antrópica como: desmatamento e lixo. 


\section{A importância do "lugar" e da "paisagem" no estudo da percepção ambiental}

O debate acerca da percepção ambiental, na atividade turística, busca compreender essa temática pelo fato de o lugar - juntamente com a afetividade - criar simbologias singulares. A percepção ocorre através da imaginação e/ou cognição dos visitantes, ao receberem influências do meio sociocultural dos espaços turísticos. Conforme Santos (1999, p. 258), o lugar possui as seguintes características:

\footnotetext{
Um cotidiano compartido entre as mais diversas pessoas, firmas e instituições-cooperação e conflito são a base da vida em comum. Porque cada qual exerce uma ação própria, a vida social se individualiza; e porque a contiguidade é criadora de comunhão, a política se territorializa, com o conforto entre organização e espontaneidade.
}

Por sua vez, a análise da percepção ambiental deve relacionar-se com o lugar por considerar aspectos subjetivos presentes nesses locais. Para Corrêa (2007), a afetividade manifesta-se no gostar dos lugares, e mesmo localizado em áreas longínquas, o indivíduo cria uma aproximação em função da afetividade.

Dessa forma, quando uma pessoa visita determinado local, pode iniciarse um processo de reverência, por causa dos sentimentos que envolvem 0 meio natural, através da apreciação de belas paisagens, como, por exemplo, praias, cachoeiras, rios, formações rochosas ou pinturas rupestres. Nessa oportunidade, pode ocorrer, ainda, a apreciação dos costumes locais, através da culinária, artesanato, e ainda do folclore; ou seja, elementos que são perceptíveis pelo conjunto dos cinco sentidos juntamente com a consciência de cada pessoa, favorecendo à criação de um espaço dotado de sensações e sentimentos.

Os estudos da percepção e do comportamento são importantes para o planejamento de determinado espaço, pois na visão de Pinheiro (2006, p. 126127), "contribuem, mediante representações e simbologias, para a 
compreensão das relações homem-ambiente, e de como o homem interage com o meio na construção de seu território, sua cultura e sua história".

\section{A relação do visitante com o parque: percepção ambiental}

A interrelação existente entre percepção e lugar é algo que deve ser considerado pelo fato de muitas características ocorrerem por causa da elaboração de um espaço repleto de aspectos subjetivos. Em outras palavras, características pessoais elaboradas em um processo contínuo e gradual, que busca internalizar as peculiaridades de uma comunidade ou de uma cidade. $O$ processo de percepção ambiental é algo importante, porque permite a elaboração de uma interpretação diferente do espaço em razão das singularidades pessoais. Para Machado (1999, p. 98), a percepção ambiental se caracteriza como "significado de espaço e frequentemente se funde com o de lugar. O que começa como espaço indiferenciado transforma-se em lugar à medida que o conhecemos melhor e o dotamos de valor".

O processo de percepção está relacionado com os elementos contidos na paisagem e na capacidade dos sentidos em assimilá-los. Dependendo do tipo de paisagem, tem-se uma organização diferente dos elementos pela existência de aspectos naturais e antrópicos.

$\mathrm{Na}$ paisagem natural, o turista pode realizar o julgamento das características naturais como forma de contemplação das belezas existentes. Deste modo, o processo perceptivo, conforme Paes-Luchiari (2001, p. 20) ocorre quando:

\footnotetext{
A sociedade ao revalorizar as paisagens naturais, constrói um novo modelo perceptivo em relação ao meio e lhe impõe novas territorialidades. É na emergência desses territórios que a sociedade mediatiza suas relações com a natureza e the atribui um valor, uma representação e um controle sobre as paisagens que os homens disputam em um campo relacional de poder.
}

O processo perceptivo ocorre de maneira significativa, em razão dos vários atributos naturais existentes. A discussão sobre a paisagem natural na 
percepção é importante, tendo em vista que essas características possibilitam a formação de uma relação de afetividade entre a paisagem e o observador.

$\mathrm{Na}$ paisagem tem-se a expressividade de elementos pertencentes às tradições culturais de um determinado povo ou comunidade. Dessa forma, a paisagem possui manifestações do imaginário social que, por sua vez, acrescentam novas características à paisagem natural. Paes-Luchiari (2007) afirma que a concepção de paisagem cultural representa a junção da técnica e do sistema de apropriação simbólico da natureza. Por conseguinte, a compreensão da paisagem cultural não pode ser realizada de forma isolada dos elementos naturais, pois é na paisagem cultural que o homem impõe seu estilo ou suas tradições, de forma que o meio natural fica submetido aos interesses de cada grupo. Em algumas situações pode ocorrer a degradação dessas paisagens, ocasionando a baixa capacidade de elaboração das simbologias e da afetividade.

$\mathrm{Na}$ paisagem cultural é possível que o observador possa assimilar alguns objetos da cultural local; ou seja, impressões que não fazem parte do seu contexto cultural. A atividade turística permite que ocorra esse fato, posto que pessoas de diferentes lugares podem formular sua compreensão sobre a paisagem cultural das localidades visitadas, pois o caráter cultural também está baseado na percepção ou na subjetividade (MELO, 2001).

É preciso entender que a percepção pode ocorrer tanto em espaços antropizados e ainda em locais dotados de características naturais, fazendo com os quais as pessoas tenham um entendimento completo. Neste sentido, Drummond (2007) afirma que o fato de se darem nomes aos componentes naturais, através da sua beleza ou de se descobrir a sua utilidade ou inutilidade surge a partir da interação entre cultura e natureza e de influências mútuas.

A percepção ambiental é um processo relevante na discussão do desenvolvimento sustentável, pois os elementos que estão contidos na percepção são importantes em virtude de os mesmos elencarem um debate novo através da valorização dos aspectos subjetivos presentes na paisagem, como os valores e as tradições que caracterizam cada lugar. 
Assim, a relação entre percepção e conservação da natureza é algo importante, haja vista que o homem elabora na sua mente uma estrutura de fatos pertencentes a uma paisagem natural e também para um grupo social, como forma de criar um respeito, criando assim uma identidade com os valores naturais e culturais

Uma informação inicial, questionada para os visitantes, foi saber se a Cachoeira do Urubu é um local agradável para passear e também para a diversão. Das oitenta pessoas questionadas, setenta e nove afirmaram que esse Parque possui atributos que possibilitam um bom passeio.

Essas informações são relevantes pelo fato de mostrarem a compreensão dos visitantes acerca desse item; ou seja, a elaboração de um espaço que proporciona satisfações pessoais durante a visitação.

A compreensão por parte dos visitantes do processo de percepção tem o intuito de criar um contexto de elaboração dos principais elementos existentes na paisagem, pois a identificação de locais "belos" ou "feios" começa a partir do entendimento individual de cada turista sobre uma determinada paisagem.

A paisagem da Cachoeira do Urubu possibilita aos visitantes uma boa impressão, estimulando-os a elaborar em suas mentes um processo de afetividade. Segundo Pinheiro (2004, p. 42), "os atributos dos espaços vivenciados são percebidos e agregados aos valores individuais, ou seja, é uma transmissão de informações entre os lugares e seus observadores".

O entendimento sobre a percepção busca elencar outros elementos que não sejam os naturais, como a limpeza, por exemplo. Na pesquisa, procurou-se saber a opinião dos visitantes sobre a limpeza no interior do Parque. Se o serviço de limpeza não for capaz de retirar o lixo oriundo da atividade turística, o visitante pode elaborar um processo de repulsa desse espaço, em razão da falta de cuidado para com a deposição do lixo. Na pesquisa de campo, as manifestações dos visitantes sobre a limpeza do Parque estão na Tabela $1 \mathrm{e}$ no Gráfico 1. 
Tabela 1 - Distribuição da opinião dos visitantes sobre a limpeza do Parque Ecológico Cachoeira do Urubu.

\begin{tabular}{l|c} 
Categoria de avaliação & Quantidade \\
\hline \hline Excelente & 1 \\
Bom & 10 \\
Regular & 40 \\
Péssimo & 26 \\
Não Sabe & 3 \\
\hline \hline Total & $\mathbf{8 0}$ \\
\hline \hline Fonte: Pesquisa direta nos meses de fevereiro e abril/2010.
\end{tabular}

$\mathrm{Na}$ Tabela 1, observa-se que a maioria dos visitantes considera que a limpeza do parque merece maior atenção, uma vez que, dos oitenta visitantes pesquisados, sessenta e seis consideraram-na de regular a péssimo, representando $82,5 \%$ das opiniões. No Gráfico 1 apresenta-se a distribuição percentual das respostas acerca desse aspecto:

Gráfico 1: Distribuição percentual das opiniões sobre a limpeza do Parque Ecológico Cachoeira do Urubu.

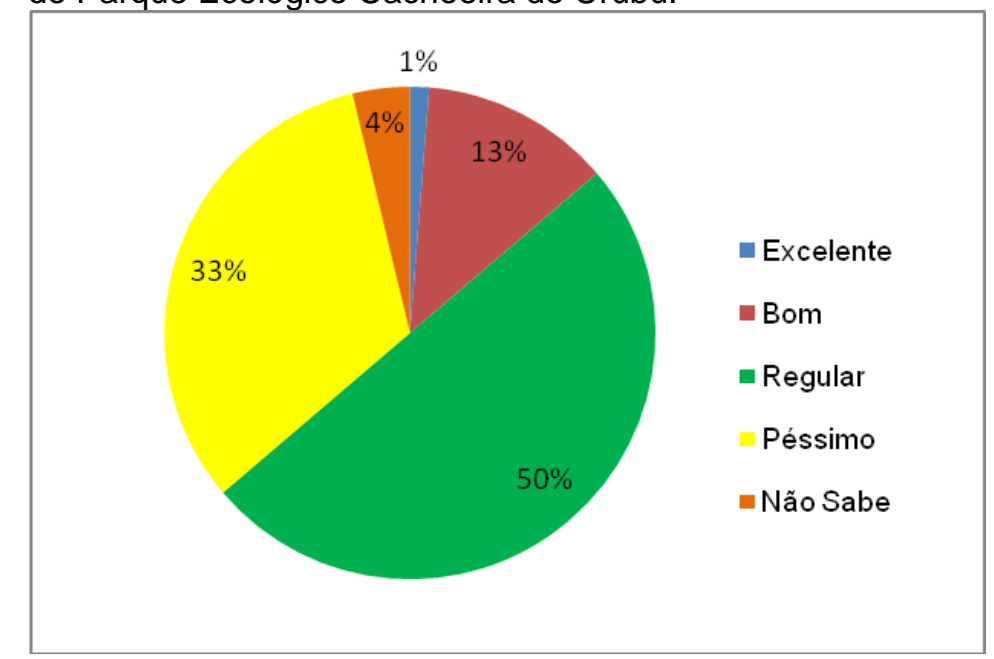

Fonte: Pesquisa direta nos meses de fevereiro e abril/ 2010. 
Para alguns visitantes entrevistados, a tendência da limpeza do Parque é encaminhar-se para o nível péssimo, pois, para essas pessoas, nada é feito por parte dos governantes nem pelos visitantes. Em períodos de grande movimentação, a limpeza do parque fica totalmente comprometida, observando-se uma paisagem degradada por essa atividade, conforme se pode observar na Fotografia 1.

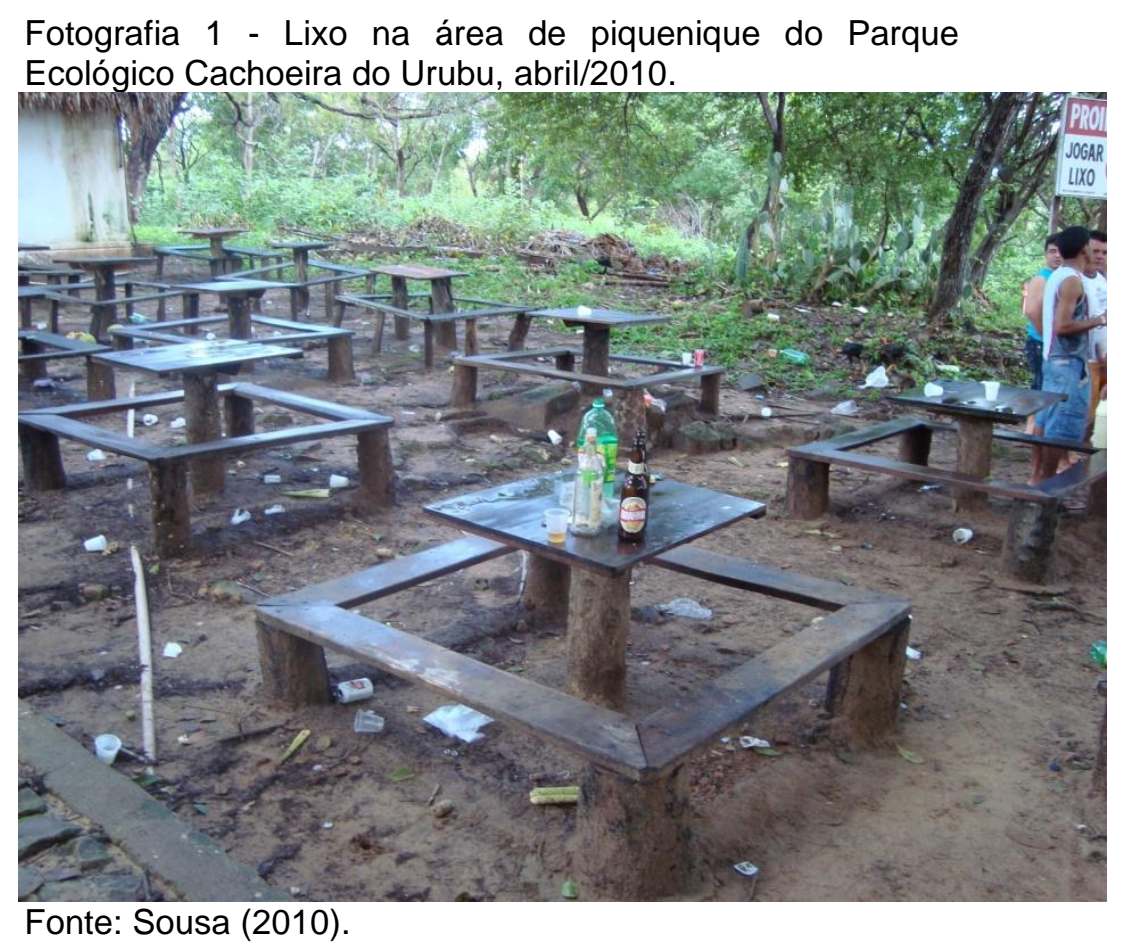

No processo perceptivo, a existência de cena, como a observada na Fotografia 1, faz com que os frequentadores tenham uma assimilação negativa da Cachoeira do Urubu em razão do lixo jogado ao chão.

Outro aspecto averiguado foi sobre o nível de conservação do Parque Ecológico. Os visitantes afirmaram que está com uma qualidade de regular a péssima. Este dado é relevante, tendo em vista que a atividade turística praticada nesse espaço traz modificações. Os dados da Tabela 2 fornecem elementos para se avaliar a percepção dos visitantes quanto a este aspecto. 
Tabela 2 - Distribuição dos visitantes segundo opinião sobre o nível de conservação do Parque Ecológico Cachoeira do Urubu.

\begin{tabular}{|c|c|c|}
\hline \multirow{2}{*}{ Nível de conservação } & \multicolumn{2}{|c|}{ Quantidade de pessoas } \\
\hline & № absoluto & $\%$ \\
\hline Excelente & 4 & 5,00 \\
\hline Bom & 16 & 20,00 \\
\hline Regular & 30 & 37,50 \\
\hline Péssimo & 23 & 28,75 \\
\hline Não sabem & 7 & 8,75 \\
\hline Total & 80 & 100,00 \\
\hline
\end{tabular}

Fonte: Pesquisa direta nos meses de fevereiro e abril/2010.

$\mathrm{Na}$ Tabela 2, pode-se observar que a maioria dos visitantes considera que o Parque Ecológico Cachoeira do Urubu possui uma conservação de regular a péssima. Assim, o processo perceptivo faz com que as pessoas compreendam elementos relacionados ao uso do parque $e$ as suas consequências, pois, dependendo do grau de conservação, formam-se diferentes valores sobre um lugar resultando em impressões variadas por causa de motivações emocionais e sensoriais diferenciados.

A conservação da paisagem do parque merece maior atenção, pois somente $5 \%$ dos entrevistados consideram o seu espaço conservado. Esse dado é preocupante, tendo em vista que apenas uma minoria conseguiu perceber algum tipo de preservação e/ou conservação. Isso indica que a forma como turismo está sendo praticado necessita de mudanças, pois, como vem sendo praticado, está contribuindo para a formação de um conjunto de imagens negativas a respeito do Parque Ecológico Cachoeira do Urubu. Para PaesLuchiari (2001, p. 18), esta situação cria:

Paisagens repugnantes que não queremos ver porque sabemos que não foram provocadas pela natureza hostil e vingativa. $O$ sujeito oculto dessas paisagens- o modo de produção e sua racionalidade de mercado - impregna de ideologia as práticas sociais que organizam os territórios valorizados ou repugnantes. 
Os aspectos relacionados à conservação da paisagem são elementos relevantes para a interpretação do espaço pelo fato de esses itens mostrarem os tipos de relações existentes entre o homem e o meio natural, ao tempo em que as pessoas estão inseridas nesse contexto por serem os causadores dessa realidade por causa de suas atitudes. Nesse caso, a atividade turística é um bom exemplo porque pode causar danos ambientais nos locais onde é praticada, e realizada de modo inadequado.

Outro aspecto averiguado junto aos visitantes relaciona-se aos estabelecimentos comerciais que estão localizados no interior do parque. Esses aspectos são relevantes, pelo fato de configurarem ações do homem que provocam mudanças na paisagem original através da instalação de edificações, com o propósito de atender as necessidades dos visitantes, relativas à alimentação, bebidas, subsidiadas pelos restaurantes (Fotografia 2).

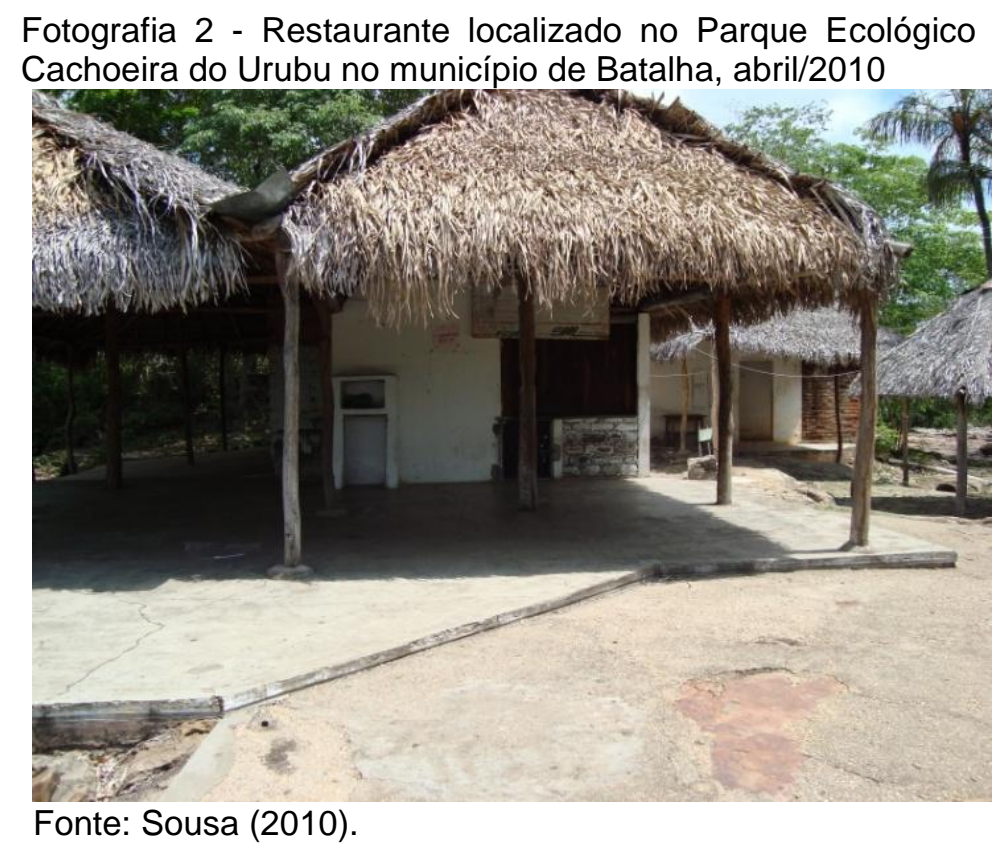

Com a realização da prática turística, há necessidade de infraestrutura para atender aos turistas. A implantação desses itens pode ocasionar uma interpretação incompleta das belezas naturais existentes. No Parque Ecológico Cachoeira do Urubu há os cenários das cachoeiras, piscinas naturais e das 
formações rochosas. Dos turistas entrevistados, $63 \%$ consideram que a passarela sobre o rio Longá e os restaurantes não provocam danos à paisagem.

Quando ocorre o processo perceptivo, o observador acaba por ressaltar os elementos que mais atraem sua atenção, de forma que estes podem influenciar na elaboração da identidade desses locais por meio dos aspectos naturais; e, em alguns casos, de fatores relacionados à cultura dos moradores.

No Parque Ecológico Cachoeira do Urubu, foi constatada a elaboração desse processo, pois os visitantes foram questionados sobre qual o atrativo do parque que influenciou sua ida. Os turistas afirmaram diversos itens, relacionados aos aspectos naturais e culturais, porém a paisagem do parque teve maior indicação.

Os itens foram: paisagem, banho no rio, artesanato, culinária, pesca e atividade de lazer, tendo em vista que esses elementos envolvem características naturais e culturais. Assim, a opinião dos visitantes sobre esses aspectos ficou distribuída conforme a Tabela 3.

Tabela 3: Distribuição dos visitantes de acordo com a identificação dos atrativos do Parque Ecológico Cachoeira do Urubu.

\begin{tabular}{l|c|c}
\multicolumn{1}{c|}{ Atrativos } & \multicolumn{2}{c}{ Quantidade de Informantes } \\
\cline { 2 - 3 } Paisagem & № Absoluto & $\%$ \\
Banho no Rio & 44 & 55,00 \\
Atividade de Lazer & 19 & 23,75 \\
Pesca & 16 & 20,00 \\
Culinária & 1 & 1,25 \\
Artesanato & 0 & 0 \\
\hline \hline Total & 0 & $\mathbf{1 0 0 , 0 0}$ \\
\hline \hline
\end{tabular}

Fonte: Pesquisa direta nos meses de fevereiro e abril, 2010. 
Conforme, a Tabela 3 pode-se perceber que $55 \%$ dos entrevistados possuem uma identidade com a paisagem do parque, fazendo com que 0 turista tenha uma possível compreensão dos elementos que estão dispostos. $\mathrm{Na}$ paisagem, podem ser encontradas diferentes formas de uso, consequentemente, o observador tenta compreender seu significado, e que o entendimento deve ocorrer de maneira homogênea, sem separação do ambiente natural do cultural, tendo em vista que o homem é considerado o principal modificador do meio natural.

A importância da paisagem na formação da percepção dos turistas é que, de acordo com Hora e Cavalcanti (2003, p. 215):

[...] o próprio turista traz consigo, enquanto observador dotado de bagagem social, cultural e noção estética particular (gosto pessoal), parte daquilo que irá satisfazer-Ihe. Esses elementos, estimulados por fatores externos, gerarão imagens e significados para o turista, que nada mais são do que representações acerca dos lugares, as quais culminarão em satisfação ou frustração mediante essa expectativa formada.

Assinale-se que a paisagem do Parque Ecológico Cachoeira do Urubu possui certa relevância para os visitantes, principalmente a natural representada pelas cachoeiras. É importante ressaltar que os elementos culturais tiveram baixas indicações.

Isso mostra que os visitantes não puderam identificar nem elaborar algum tipo de vínculo pessoal para com as tradições culturais da população local. Contudo, os moradores do interior do Parque e das comunidades circunvizinhas praticam a pescaria nos períodos de cheia do rio Longá.

Outro fato questionado para os visitantes diz respeito aos valores simbólicos existentes durante a sua permanência na Cachoeira do Urubu, pois no processo de percepção pode ocorrer o fortalecimento dos vínculos afetivos. $\mathrm{O}$ ato de observar permite que o observador possa retirar alguns elementos da paisagem natural ocasionando assim a elaboração das imagens do lugar.

No caso do Parque Ecológico Cachoeira do Urubu, os seus visitantes revelaram ter um elo afetivo para com esse espaço, tendo em vista que $74 \%$ dos entrevistados afirmaram possuir uma simbologia, especialmente com às 
águas do rio Longá ou as quedas d'água. Essa atitude deveria ser fortalecida a cada temporada; lamentavelmente não há nessa UC nenhum projeto com essa finalidade, que possa vir a realizar-se através da educação ambiental.

Essa informação representa um importante dado sobre a relação turista e meio ambiente, pelo fato de o turismo do parque propiciar a elaboração de um contexto dotado de sentimentos. Dessa forma, a construção dos valores simbólicos é um fato normal. E esse conjunto de simbologias pode ser positivo ou negativo, posto que, no Parque Ecológico Cachoeira do Urubu, os visitantes possuem uma assimilação favorável sobre esse espaço. Para Neiman (2008, p. 44):

\begin{abstract}
A percepção edênica dos destinos ecoturísticos, carregada de simbolismo, remete seus adeptos à busca de um ideal de paisagem onde a ética e a estética têm papel de destaque. Os vínculos com a localidade e com as outras pessoas, renovados sobre outra perspectiva, passam a orientar as ações dos sujeitos.
\end{abstract}

Outro dado constatado na pesquisa relaciona-se com a quantidade de pessoas que visitam o parque nos períodos da alta estação. Como não há um controle da entrada dos visitantes nem um ordenamento de distribuição no interior do parque, ocorrem maiores concentrações em algumas áreas do parque, de tal forma que dificulta o bom desenvolvimento da prática turística. Com relação a esse aspecto, 65\% dos entrevistados não aprovam a lotação verificada, pois consideram que assim não proporciona bem-estar, impedindo a elaboração de uma melhor interpretação dos elementos presentes na paisagem.

Assim, a quantidade de visitantes no Parque Ecológico Cachoeira do Urubu no período de alta estação é um aspecto negativo, pois ocorre uma lotação, que, por sua vez, impede a melhor contemplação e vivência do lugar.

$\mathrm{Na}$ formação do processo perceptivo, o observador deve interpretar os espaços turísticos, de modo a caracterizar os aspectos naturais e culturais existentes no lugar. As experiências vivenciadas pelos visitantes no Parque Ecológico Cachoeira do Urubu foram classificadas conforme os dados no Gráfico 2. 


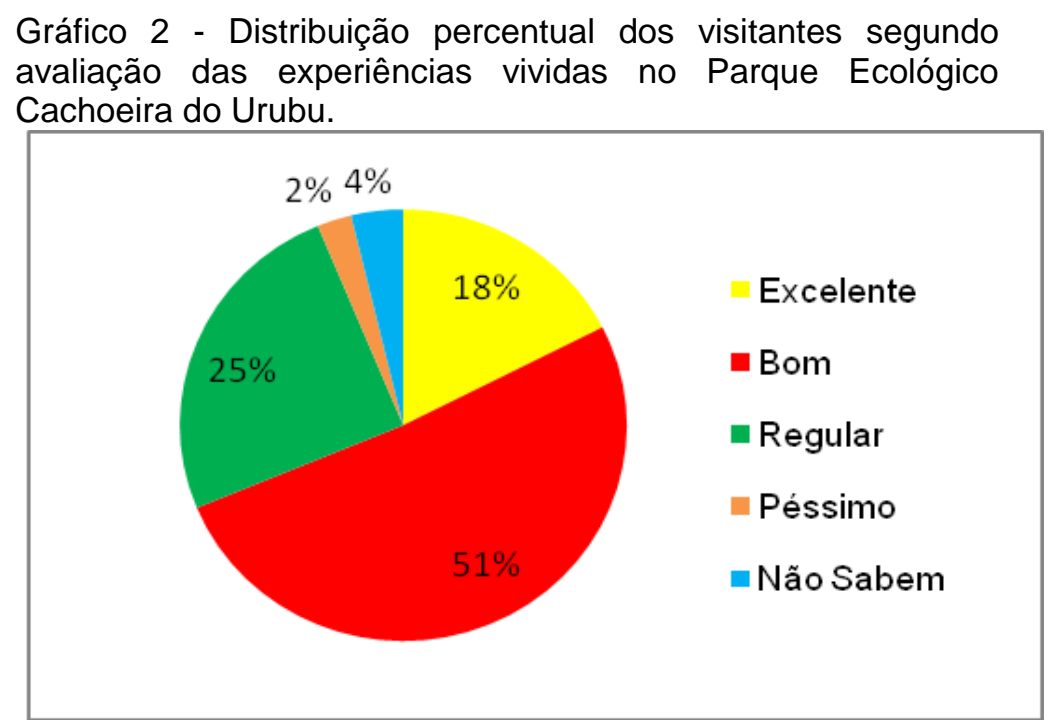

Fonte: Pesquisa direta nos meses de fevereiro e abril/2010.

As experiências vivenciadas pela maioria dos visitantes do Parque Ecológico Cachoeira do Urubu foram consideradas de bom a excelente, representando as opiniões de dois terços dos visitantes.

Dessa forma, torna-se um processo relevante no fortalecimento da percepção de um lugar, em decorrência da variedade de elementos como significados, criatividade e estética, sendo que esta última característica relaciona-se com a identificação de elementos na paisagem, que possuam características contrastantes, como, por exemplo: uma frondosa mata, um rio poluído ou o lixo colocado de forma inadequada, o que dificulta a visão do turista na contemplação da paisagem.

Assim, a elaboração da experiência é algo que depende da capacidade pessoal do observador em entender os fenômenos que estão dispostos no espaço, e, dessa forma, criar uma relação de simbologia e intimidade. Porém na pesquisa, foi constatado que alguns aspectos contribuíram para manifestações de insatisfações com a visita ao Parque, como a falta de acondicionamento adequado do lixo, infraestrutura precária, desorganização, ausência do poder público (com ações em serviços de limpeza, assistência em socorro médico e orientação aos visitantes) e excesso de visitantes em determinados locais. Esses problemas foram citados por $60 \%$ dos visitantes como causadores da insatisfação na visita ao Parque. 
Percebe-se então que o turista, quando esteve realizando o seu passeio no parque, conseguiu interpretar elementos que são essenciais para melhorar atividade turística. A esse respeito uma turista assim se manifestou: "a cada ano que eu venho aqui com a minha família a gente espera melhorias para a cachoeira, e nada acontece". Logo, a percepção dos visitantes é capaz de identificar elementos que estejam prejudicando o bom desenvolvimento dessa atividade.

\section{Conclusão}

A percepção por parte dos visitantes no Parque Ecológico é resultante da elaboração de sua cognição de elementos relacionados com a noção de conservação e a identidade do lugar. Dessa forma, 98,75\% dos visitantes consideraram o parque um local agradável para passear. Esse dado é importante, pois mostra que os visitantes encontram elementos na paisagem que torna sua permanência agradável, como, por exemplo, as quedas d'água.

$\mathrm{Na}$ análise sobre a percepção dos visitantes, também é possível serem identificadas ações que causam a degradação na paisagem, como acondicionamento inadequado do lixo. O processo perceptivo ali encontrado elenca essa importante característica, em razão de os visitantes terem uma análise sobre o nível de limpeza e a conservação encontrada na Cachoeira do Urubu, revelando assim que a atividade turística no Parque é predatória.

Outro aspecto relacionado com a percepção do parque diz respeito ao fortalecimento da identidade do lugar. Na pesquisa, foi compreendido que os visitantes possuem esses elementos, pelo fato de elencarem o atrativo mais importante, ou seja, o valor simbólico do parque, a experiência com o ambiente, e sua opinião sobre os atrativos que mais gostavam de observar no parque. Nesse último aspecto, tem-se um dado importante, pois, dos oitenta visitantes entrevistados, $55 \%$ elencarem a paisagem como um aspecto relevante na admiração das potencialidades ambientais existentes.

Assim, o Parque Ecológico Cachoeira do Urubu depende de seus atrativos naturais para o bom desenvolvimento do turismo. Desta forma, o uso consciente do patrimônio natural é de grande relevância para a continuação da 
atividade turística. As pessoas que visitam o parque reconhecem que é preciso solucionar vários problemas existentes, a exemplo do lixo em decorrência da atividade turística, haja vista que $60 \%$ dos turistas consultados não ficam satisfeitos com a visita, em razão dos problemas ambientais encontrados. É preciso a implantação de um programa de educação ambiental com o propósito de mudar os atos que provoquem danos ao meio natural, consequentemente surgindo uma melhor identidade do visitante e preservação do Parque.

\section{Referências}

AYOADE, J. O. Introdução à climatologia. 8. ed. Rio de Janeiro: Bertrand Brasil, 2002.

CASTELLO, Lineu. A percepção de lugar: repensando o conceito de lugar em arquitetura-urbanismo. Porto Alegre: PROPAR-UFRGS, 2007.

CAVALCANTE, S.; MACIEL, R. H. Métodos de avaliação da percepção ambiental. In: PINHEIRO, J. Q.; GÜNTHER, H. (Orgs.). Métodos de pesquisa nos estudos pessoa- ambiente. São Paulo: Casa do Psicológico, 2008. p. 149- 180.

CORRÊA, Roberto Lobato. Espaço um conceito chave da geografia. In: CASTRO, Iná Elias de; GOMES, Paulo César da Costa; CORRÊA, Roberto Lobato (Org.). Geografia: conceitos e temas. 10. ed. Rio de Janeiro: Bertrand Brasil, 2007. p. 15-48.

DEL RIO, Vicente. Cidade da Mente, Cidade Real: percepção ambiental e revitalização na área portuária do RJ. In: DEL RIO, Vicente; OLIVEIRA, Lívia (Org.). Percepção ambiental: a experiência brasileira. 2. ed. São Carlos: Studio Nobel, 1999. p. 3-22.

DRUMMOND, José Augusto. Patrimônios natural e cultural: endereços distintos nos espaços urbanos, rurais e selvagens. In: PAES-LUCHIARI, Maria Teresa Duarte; BRUHNS, Heloísa Turini; SERRANO, Célia (Org.). Patrimônio, natureza e cultura. São Paulo: Papirus, 2007. p. 103-116.

HORA, Alberto Segundo Spíndola da; CAVALCANTI, Keila Brandão. Turismo pedagógico: conversão e reconversão do olhar. In: REJOWSKI, Miriam; COSTA, Benny Kramer (Org.). Turismo contemporâneo: desenvolvimento, estratégia e gestão. São Paulo: Atlas, 2003. p. 207-226.

LEITE, Francisco Tarciso. Metodologia científica: métodos e técnicas de pesquisa: monografias, dissertações, teses e livros. Aparecida-SP: Ideias \& Letras, 2008. 
MACHADO, Carmen Silvia de Lemos Menezes; MACIEL, Tania Maria de Freitas Barros. O uso da percepção ambiental em jardins botânicos. Olam Ciência \& Tecnologia. Rio Claro/SP, Brasil, ano 7, v. 7, n. 1, p. 295-313, maio, 2007

MACHADO, Lucy Marion Calderini Philadelpho. Paisagem valorizada: a serra do mar como Espaço e como Lugar. In: DEL RIO, Vicente; OLIVEIRA, Lívia (Org.). Percepção ambiental: a experiência brasileira. 2. ed. São Carlos: Studio Nobel, 1999. p. 97-121.

MELO, Vera Mayrinck. Paisagem e simbolismo. In: ROSENDAHL, Zeny; CORRÊA, Roberto Lobato. (Org.). Paisagem, imaginário e espaço. Rio de Janeiro: EdUERJ, 2001. p. 29-48.

MORAES, Antônio Carlos Robert de. Ideologias geográficas: espaço, cultura e política no Brasil. 3. ed. São Paulo: Hucitec, 1996.

NEIMAN, Zysman. Ecoturismo e educação ambiental em unidades de conservação: a importância da experiência dirigida. In: COSTA, Nadja Maria da; NEIMAN, Zysman; COSTA, Vivian Castilho (Org.). Pelas trilhas do ecoturismo. São Carlos: Rima, 2008. p. 33-48.

OLIVEIRA, Lívia de; MACHADO, Lucy Marion Calderini Philadelpho. Percepção, cognição, dimensão ambiental e desenvolvimento com sustentabilidade. In: GUERRA, Antônio José Teixeira; VITTE, Antônio Carlos. (Org.). Reflexões sobre a geografia física no Brasil. Rio de Janeiro: Bertrand Brasil, 2004. p. 129-149.

OKAMOTO, Jun. Percepção ambiental e comportamento: visão holística da percepção ambiental na arquitetura e na comunicação. São Paulo: Editora Mackenzie, 2002.

PAES-LUCHIARI, Maria Teresa. A (re)significação da paisagem no período contemporâneo. In: ROSENDAHL, Zeny; CORRÊA, Roberto Lobato (Org.). Paisagem, imaginário e espaço. Rio de Janeiro: EdUERJ, 2001. p. 9-28.

. Turismo e patrimônio natural no uso do território. In: PAES-LUCHIARI, Maria Teresa Duarte; BRUHNS, Heloísa Turini; SERRANO, Célia (Org.). Patrimônio, natureza e cultura. São Paulo: Papirus, 2007. p. 25- 46.

PIAUÍ. Secretária de Turismo. Programa de regionalização do turismo. Teresina, 2009. 18 slides.

PINHEIRO, Evandro da Silva. Percepção ambiental e atividade turística no Parque Estadual do Guartelá - Tibagi- PR. Revista RA'E GA, Curitiba, n. 12, p. 121-134, 2006. 
Percepção ambiental e a atividade turística no Parque Estadual do Guartelá- Tibagi, PR. 2004. 135 f. Dissertação (Mestrado em Geografia), Universidade Federal do Paraná. Curitiba, 2004.

SANTOS, Milton. A natureza do espaço: espaço e tempo: razão e emoção. 3. ed. São Paulo: Hucitec, 1999.

SILVA, Cláudia Germana Barbosa da. Estado de conservação dos fragmentos florestais na Área de Proteção Ambiental-APA estadual Cachoeira do Urubu (PI) e avaliação de indicadores para monitoramento ambiental. 2008. 100f. Dissertação (Mestrado em Desenvolvimento e Meio Ambiente), Universidade Federal do Piauí. Teresina, 2008.

SOUSA, Accyolli Rodrigues Pinto de. Percepção ambiental no turismo do Parque Ecológico Cachoeira do Urubu nos municípios de Esperantina e Batalha no Estado do Piauí. 2010. 2 fotografias digital color.

TUAN, Yi-Fu. Espaço e lugar: a perspectiva da experiência. Tradução Lívia Andrade. São Paulo: Difel, 1983.

Topofilia: um estudo da percepção, atitudes e valores do meio ambiente. Tradução Lívia Andrade. São Paulo: Difel, 1980. 